\title{
Iodine concentration in common potable water sources in the estates of Ratnapura district and thyroid status of children
}

\author{
Visula Abeysuriya ${ }^{1}$, Ananda Rajitha Wickremasinghe ${ }^{1}$, Priyantha Julian Perera ${ }^{2}$, Anuradhani Kasturiratne ${ }^{1}$
}

Sri Lanka Journal of Child Health 2012; 41(4): 176-179

\begin{abstract}
Introduction: Iodine deficiency is the single most important cause of hypothyroidism. Drinking water is an important source of iodine for humans.

Objective: To identify the common potable water sources available to the estate population in the Ratnapura District, to determine the iodine concentrations in different water sources and to ascertain the relationship between water iodine concentrations and thyroid status of children 5 to 9 years of age.
\end{abstract}

Method: A descriptive cross sectional study was carried out in three phases in 20 randomly selected estates in the Ratnapura district of Sri Lanka from September to November 2009. In phase 1, 1,683 households in the selected estates were surveyed to identify the drinking water sources. In phase 2, blood samples from 519 randomly selected children aged 59 years from the same estates were taken to assay TSH levels after obtaining informed written consent from parents. In phase 3, water samples from 23 identified sources (wells, rivers and springs) were analysed for iodine levels by the catalytic reduction method. Water sources were grouped on elevation above mean sea level. The mean TSH levels and water iodine concentrations were correlated.

Results: The main source of drinking water was spring water $(83.7 \%)$. Spring water at low altitudes had significantly higher iodine concentrations than that located at higher altitudes $(\mathrm{p}<0.01)$. The mean iodine concentration in spring water was significantly lower than that in other sources $(\mathrm{p}<0.001)$. There was no association between the mean TSH levels of children and the altitudes at which they lived $(p>0.05)$. There was no significant association between TSH levels of children and iodine concentration in drinking water $(\mathrm{p}>0.05)$.

${ }^{1}$ Department of Public Health, ${ }^{2}$ Department of Paediatrics, Faculty of Medicine, University of Kelaniya, Ragama, Sri Lanka

(Received on 11 January 2012: Accepted after revision on 24 February 2012)
Conclusions: The main potable water source available to the population in the Ratnapura District was spring water $(84 \%)$. The mean iodine concentration of spring water was significantly lower as compared to other water sources. There was no significant association between serum TSH levels in children 5 to 9 years of age and iodine concentration in drinking water.

(Key words: Water iodine concentration; children; TSH levels; Sri Lanka)

\section{Introduction}

Iodine deficiency leading to hypothyroidism is the single most important cause of preventable brain damage and mental retardation. The clinical and sub clinical manifestations of iodine deficiency, collectively identified as iodine deficiency disorders (IDD), affect all stages of human growth and development ${ }^{1,2}$. Chronic iodine deficiency results in low serum thyroxin levels which stimulate secretion of thyrotrophin stimulating hormone (TSH) from the pituitary. Persistent stimulation of the thyroid gland by TSH results in a goitre. There have been many studies on goitre prevalence in Sri Lanka ${ }^{3}$. The first systematic assessment of IDD, conducted in 1986, revealed a goitre prevalence of $18.2 \%$. After 10 years of the salt iodization programme, goitre prevalence in Sri Lanka decreased to $3.8 \%$ in $2005^{5}$.

The daily iodine requirement for an adult is 100$200 \mu \mathrm{g}$ and $90 \mu \mathrm{g}$ for children under 6 years $^{6}$. This indicates that children have a relatively higher requirement of iodine. The main sources of iodine for humans are seafood and drinking water ${ }^{7}$. In areas towards the centre of the country, seafood consumption is low due to higher cost and low availability. Therefore, the amount of iodine in water becomes more important for people living in these areas. In areas with high rainfall, soil iodine is washed off, resulting in low concentrations of iodine in drinking water. The plantation sector of Sri Lanka is mainly located in areas with high rainfall and away from coastal areas. However, due to the salt iodization programme any deficiency resulting from low concentration of iodine in drinking water is expected to be corrected. 
There are very few studies, if any, conducted in Sri Lanka on water iodine concentrations.

\section{Objectives}

- To identify the common potable water sources available for the estate populations in the Ratnapura District,

- To determine the iodine concentration in different water sources and

- To ascertain the relationship between water iodine concentrations and thyroid status of 5 to 9 year old children.

\section{Method}

The study was conducted in 3 phases. In phase 1, 20 estates in the Ratnapura district were randomly selected. In each estate, a list of households where 5 to 9 year old children were resident was obtained from the plantation welfare office. 1,683 households were randomly selected from the list. From each estate, 2 health and welfare staff members were recruited as research assistants and were given training on data collection using a pre-tested questionnaire. The research assistants visited selected households, obtained socio-demographic details and identified the potable water sources.

In phase 2, 519 children 5-9 years of age from the same households were randomly selected. The objectives of the study were explained to parents and informed written consent was obtained from parents and/or guardians to collect a blood sample each from the selected children. The cluster medical doctor, nurses and nursing sisters from the $\mathrm{MOH}$ office and estate medical staff were recruited to obtain blood samples from children. The selected individuals were experienced and qualified to draw blood by venipuncture from children. An awareness programme was conducted for the recruited heath staff regarding the objectives and the importance of the study; they were also given refresher training in drawing blood samples from children under aseptic conditions.

Parents were requested to bring selected children to the estate dispensary on a given date. From each child, $3 \mathrm{ml}$ of venous blood was drawn using disposable needles and syringes. The blood samples were transferred to "BD VACUTINER SST" II ADVANCE" in which serum gets automatically separated. The blood samples were kept at $4^{0} \mathrm{C}$ until they were transported to the laboratory. Serum TSH levels were assayed using the "Immulite $3^{\text {rd }}$ generation TSH Chemiluminescent Immunometric assay" $^{\prime \prime}$.

In phase 3 of the study, 23 water sources used by the estate people were identified, which included wells, rivers and springs. Five hundred millilitres of water were collected from each source into an autoclaved, round and narrow necked polypropylene bottles. Samples were transported to the laboratory in a cool box maintained at $4^{0} \mathrm{C}$ and analyzed for iodine levels using the catalytic reduction method. The mean TSH levels of children and water iodine concentrations were correlated to ascertain a causal relationship. Data analysis was done using SPSS version 13 software. Frequency distributions were used to describe the data. ANOVA and students t-tests were used to assess statistical significance.

Ethical clearance to conduct the study was obtained from the Ethics Committee of the Faculty of Medicine, University of Kelaniya, Sri Lanka. Permission to conduct the study was obtained from the regional plantation companies and relevant managers of the selected estates.

\section{Results}

Table 1 shows the sources of drinking water in the plantation sector of the Ratnapura district.

Table 1

Source of drinking water of households in estates of Ratnapura district

\begin{tabular}{|l|c|}
\hline \multicolumn{1}{|c|}{ Variable } & Number (\%) \\
\hline Pipe borne (from public supply) & $246(14.6)$ \\
\hline Springs (Collected to tanks) & $1408(83.7)$ \\
\hline Wells & $3(0.2)$ \\
\hline Rivers & $26(1.5)$ \\
\hline
\end{tabular}

The iodine concentration in spring water by elevation is given in Table 2 . 
Table 2

Iodine concentration of spring water by elevation

\begin{tabular}{|c|c|c|c|c|}
\hline $\begin{array}{c}\text { Elevation (in } \\
\text { metres) }\end{array}$ & $\begin{array}{c}\text { Number of } \\
\text { samples }\end{array}$ & $\begin{array}{c}\text { Mean water iodine } \\
\text { concentration }(\boldsymbol{\mu} / \mathbf{d} \mathbf{l})\end{array}$ & Median & SD \\
\hline $100-200$ & 2 & 36.00 & 36.00 & 5.657 \\
\hline $201-300$ & 8 & 16.25 & 18.00 & 6.519 \\
\hline $301-400$ & 4 & 7.75 & 7.50 & 4.113 \\
\hline$>400$ & 6 & 3.83 & 4.00 & 1.602 \\
\hline
\end{tabular}

There was a significant decrease in iodine concentrations in spring water with increasing elevation $(\mathrm{p}<0.001)$. Table 3 shows the comparison of iodine levels in spring water and other sources of drinking water.

Table 3

Comparison of iodine levels of different water sources

\begin{tabular}{|l|c|c|c|}
\hline \multicolumn{1}{|c|}{ Water source } & $\begin{array}{c}\text { Mean Iodine } \\
\text { concentration }(\boldsymbol{\mu} \mathrm{g} / \mathrm{dl})\end{array}$ & Standard Deviation $(\boldsymbol{\mu g} / \mathbf{d l})$ & $\begin{array}{l}\text { P value } \\
\text { (Using Students } \\
\text { t-test) }\end{array}$ \\
\hline $\begin{array}{l}\text { Springs } \\
(\mathbf{n}=\mathbf{2 0})\end{array}$ & 12.80 & 10.63 & 0.0001 \\
\cline { 1 - 2 } $\begin{array}{l}\text { Other sources (e.g. well, river) } \\
(\mathbf{n}=\mathbf{3})\end{array}$ & 130.00 & 112.12 & \\
\hline
\end{tabular}

The mean iodine concentration in spring water was significantly lower than that in other sources $(p<0.001)$. The mean TSH levels of children at different altitudes are shown in Table 4.

\section{Table4}

TSH levels of children resident at different altitudes

\begin{tabular}{|c|c|}
\hline $\begin{array}{c}\text { Elevation (above } \\
\text { mean sea level) }\end{array}$ & $\begin{array}{c}\text { Mean }(\mathbf{+} \text { SD) TSH level } \\
(\boldsymbol{\mu} \mathbf{I U} / \mathbf{m l})\end{array}$ \\
\hline $101-200 \mathrm{~m}(\mathrm{n}=2)$ & $1.785(0.148)$ \\
\hline $201-300 \mathrm{~m}(\mathrm{n}=8)$ & $2.211(0.637)$ \\
\hline $300-401 \mathrm{~m}(\mathrm{n}=4)$ & $2.170(0.459)$ \\
\hline$>401 \mathrm{~m}(\mathrm{n}=6)$ & $2.036(0.170)$ \\
\hline
\end{tabular}

There was no association between the mean TSH levels of children and the altitudes at which they lived $(\mathrm{p}=0.69, \mathrm{p}>0.05)$.

There was no statistically significant association between the mean TSH concentrations of children and iodine concentrations in spring water. $(p=0.46$, $\mathrm{p}>0.05)$.

\section{Discussion}

Iodine is an essential element for humans, as it is required for the synthesis of thyroxin. It is well established that deficiency of iodine results in clinical and subclinical hypothyroidism with all its consequences. As availability of seafood is limited for people living in the plantation areas of Sri Lanka, having an adequate iodine concentration in drinking water is considered important.

In this study, springs were the main source of drinking water for the people in the plantation sector of the Ratnapura district. Iodine concentration in spring water was significantly lower than that of water from sources such as wells and rivers. Further, the iodine concentration in spring water decreased with increasing elevation. As most estates involved in the plantation sector are located at high altitudes (>2000 feet above mean sea level), it may be assumed that drinking water is unlikely to provide the recommended iodine requirements for people living in these areas.

Iodine concentrations in spring water were not associated with TSH levels. It was expected that TSH levels of children would increase with increasing altitude given the fact that iodine concentrations in spring water decreased with increasing elevation. Hence, it is surmised that these children have 
obtained adequate amounts of iodine from some other source. The importance of strengthening and continuing the salt iodization programme to prevent iodine deficiency disorders in children especially in this particular vulnerable sector is emphasized.

\section{Conclusions}

- The main potable water source available to the population in the Ratnapura District was spring water $(84 \%)$.

- The mean iodine concentration of spring water was significantly lower as compared to other water sources.

- There was no significant association between serum TSH levels in children 5 to 9 years of age and iodine concentration in drinking water.

\section{Acknowledgements}

We thank the Regional Plantation Companies and estate managements for granting permission to conduct this study. We also thank the public health staff and the estate health and welfare staff for sampling, drawing blood samples and conducting the study. We greatly appreciate the contribution made by parents and children included in this study as without them this study would not have been a reality.

\section{References}

1. Kelly FC, Snedden WW. WHO Monograph Series. Prevalence and Geographical Distribution of Endemic Goitre, Geneva. 1960; 27-233.
2. Ying-li Lu, Ning-jian Wang, Lan Zhu, Guo-xing Wang, Hui Wu, Lin Kuang, and Wen-ming Zhu. Investigation of iodine concentration in salt, water and soil along the coast of Zhejiang, China. Journal of Zhejiang University Science 2005; 6 (12):1200-5. http://dx.doi.org/10.1631/jzus.2005.B1200

3. Fuge R, Johnson CC. The geochemistry of iodine. Journal of Environmental Geochemistry Health 1986; 8:31-54.

4. Wilson DC. Goitre in Ceylon and Nigeria. British Journal of Nutrition 1954; 8: 90- 9. http://dx.doi.org/10.1079/BJN19540018

5. Mahadeva, K. , Shanmuganathan S. S. The etiology of endemic goiter in Ceylon. British Journal of Nutrition 1967; 21: 341. http://dx.doi.org/10.1079/BJN19670036

6. Assessment of the iodine deficiency disorders and monitoring their elimination. Geneva, (WHO/NHD/01.1) 2001.

7. Water Quality Fact Sheet: Iodine. British Geological Survey, 2000; 1-4.

8. IMMULITE: Third Generation TSH; Siemens Medical Solutions.5210 Pasific Concourse Drive, Los Angeles, CA 90045-6900, USA.2006. 